\title{
RESEÑA DE MONEREO PÉREZ, JOSÉ LUIS, OJEDA AVILÉS, ANTONIO, GUTIÉRREZ BENGOECHEA, MIGUEL: REFORMA DE LAS PENSIONES PÚBLICAS Y PLANES PRIVADOS DE PENSIONES, EDICIONES LABORUM, 2021, 124 PÁGS.
}

\author{
Matthieu Chabannes* \\ Universidad Complutense de Madrid, España
}

En junio de 2020 José Luis Monereo Pérez (Catedrático de Derecho del Trabajo y de la Seguridad Social de la Universidad de Granada y Presidente de la Asociación Española de Salud y Seguridad Social) y Guillermo Rodríguez Iniesta (Profesor Titular de Derecho del Trabajo y de la Seguridad Social) publicaban La pensión de jubilación que constituye una revisión completa, rigurosa y critica del régimen jurídico de la jubilación en todas sus modalidades ${ }^{1}$.

Un año después el profesor Monereo Pérez presenta sus últimas reflexiones sobre el tema con la publicación de una nueva monografía que se titula Reforma de las pensiones públicas y planes privados de pensiones. Para esta ocasión le acompañan otros dos grandes académicos con mucha autoridad en la materia como son Antonio Ojeda Avilés (Catedrático de Derecho del Trabajo y de la Seguridad Social en la Universidad de Sevilla; Profesor Honorario de la Universidad Internacional de Andalucía en Sevilla; Presidente de Honor de la Asociación Española de Salud y Seguridad Social) y Miguel Gutiérrez Bengoechea (Profesor Titular de Derecho Financiero y Tributario en la Universidad de Málaga y Profesor Tutor de la UNED de Málaga).

\footnotetext{
${ }^{1}$ Monereo Pérez, J.L.; Rodríguez Iniesta, G.: La pensión de jubilación, Ediciones Laborum, Murcia, 2020. La monografía fue reseńada por Chabannes, M. en Revista de Derecho de la Seguridad

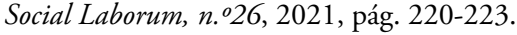

\footnotetext{
* Correspondencia a: Matthieu Chabannes. C/Embajadores, 91, 1 ext dcha, Madrid (Madrid), España. — matthcha@ucm.es — https: //orcid.org/0000-0002-9295-923X

Cómo citar: Chabannes, Matthieu. (2021). "Reseña de Monereo Pérez, J.L., Ojeda Avilés, A., Gutiérrez Bengoechea, M.: Reforma de las pensiones públicas y planes privados de pensiones, Ediciones Laborum, 2021, 124 págs..); Lan Harremanak, 45, 308-312. (https: //doi.org/10.1387/lan-harremanak.22758).
}

Recibido: 26 abril, 2021; aceptado: 29 abril, 2021.

ISSN 1575-7048 - elSSN 2444-5819 / (c) 2020 UPV/EHU

(c) (i) Esta obra está bajo una licencia

Creative Commons Atribución 4.0 Internacional 
La obra se enmarca en dos Proyectos de Investigación Estatales sobre «Envejecimiento activo y Vida Laboral: Trabajadores Maduros y Pensiones Productivos» de la Universidad de Granada y «Retos, reformas y financiación del sistema de pensiones ¿¿Sostenibilidad versus suficiencia?» de la Universidad de Málaga.

El libro se estructura en seis capítulos que se completan con una relación de la bibliografía consultada.

El primer capítulo parte de una reflexión sobre la importancia de que cualquier reforma en materia de pensiones debe acometerse respetando los artículos 41 y 50 de la Constitución Española. En este sentido, el factor de sostenibilidad establecido en la Ley 23/2013, de 23 de diciembre, además de marcar una ruptura sin precedentes en el dialogo social, supuso una disminución de la cuantía de las prestaciones alejándose de los principios constitucionales de mantener y garantizar unas pensiones públicas adecuadas y suficientes. Ello no infringiría solamente nuestro marco constitucional, sino que también sería contrario a lo establecido en la Carta Social Europa, el Código Europeo de la Seguridad Social o el Convenio n. ${ }^{\circ} 102$ de la OIT. Los autores recuerdan que nuestra Constitución obliga a los poderes públicos a mantener un sistema público de pensiones y para ello proponen la articulación de una política estatal no tanto centrada en reducir el gasto como en incrementar los ingresos buscando nuevas fuentes de financiación a través por ejemplo de un incremento selectivo de cotizaciones sociales y/o de impuestos.

El segundo capítulo comienza resaltando la idea de que, a pesar de no tener competencias sustantivas en materia de Seguridad Social, las instituciones políticas de la Unión Europea a través de la técnica de Soft Law han conseguido imponer las políticas de Derecho del Trabajo y de la Seguridad Social. La constitución social de los países miembros se subordina a la constitución económica de la UE. Para ilustrar esta idea, los autores se apoyan en el Plan de Recuperación, Transformación y Resiliencia: reformas en el ámbito laboral y de pensiones que nuestro gobierno ha enviado a Bruselas y en las condiciones exigidas por las instituciones europeas a cambio de recibir los fondos europeos de recuperación de las consecuencias del COVID-19. Los autores critican la adopción de medidas que supongan una reducción del nivel de protección de las pensiones públicas para así facilitar la expansión de los planes privados de pensiones. Se insiste en la utilidad complementaria de los sistemas privados de ahorro, pero en ningún caso estos deben ser sustitutivos de los sistemas públicos.

El tercer capítulo confronta los problemas estructurales de los sistemas de pensiones en relación con el contexto actual marcado por la crisis socioeconómica derivada de la Pandemia COVID-19. Desde una perspectiva a nivel comunitario, los autores resaltan como aprendiendo del fracaso de la experiencia pasada con políticas restrictivas del gasto para hacer frente a la crisis económica de 2008, la Unión Europea ha dado un giro de 180 grados, apos- 
tando esta vez por una política de expansión del gasto público con la creación de fondos europeos para salir de la crisis y mitigar los dańos sociales y económicos causados por la pandemia. Una respuesta acertada en tanto en cuanto muestra un equilibrio entre economía y justicia social evitando así que "las libertades económicas prevalezcan sobre los derechos sociales fundamentales». En este sentido, se plantea la necesidad de «replantearse seriamente algunos de los enfoques, análisis y propuestas que se perciben en el Libro Verde de 2010 y en el Libro Blanco de 2012 de la Comisión Europea». Dentro del modelo multipilar con tres niveles, la Unión apuesta fundamentalmente por los sistemas privados individuales como demuestra la iniciativa comunitaria a través del Reglamento de la UE de 2019 relativo a un Producto Paneuropeo de Pensiones Individuales. Sin embargo, se recuerda de nuevo como las épocas de crisis han puesto de manifiesto «la fragilidad de estos instrumentos de previsión privada para garantizar el mantenimiento de la rentabilidad de los derechos consolidados y la continuidad de aportaciones y contribuciones económicas de los promotores, partícipes y beneficiarios». La última parte del capítulo hace referencia a la última Ley de Presupuestos Generales del Estado y concretamente a las modificaciones introducidas para los beneficios fiscales concedidos en el momento de contratar un plan de pensiones de empleo, cumpliendo en parte las líneas marcadas por Bruselas.

Las páginas que conforman el cuarto capítulo están dedicadas al estudio del segundo pilar del modelo multipilar de pensiones que estaría conformado por los planes de empleo muy arraigados en los países nórdicos como Suecia o Dinamarca. Concretamente los autores se centran en el modelo desarrollado por el Reino de los Países Bajos que en numerosos estudios ha sido calificado como uno de los mejores del mundo. Después de presentar su estructura y funcionamiento, los autores resaltan algunos de los problemas que plantea el modelo como la obligatoriedad de sus planes que ha sido denunciada en varias ocasiones ante el Tribunal de Justicia de la Unión Europea; o el papel desempeńado por cada una de las partes suscritas en su gestión, etc.

El quinto capítulo se centra en la Ley 11/2020, de 30 de diciembre de Presupuestos Generales del Estado para el año 2021 y en las importantes modificaciones que su aprobación ha supuesto para la fiscalidad de los planes de pensiones individuales y particularmente para los planes de empleo. A pesar del intento por parte del legislador de adoptar medidas para fomentar y desarrollar estos planes de pensiones de empleo entre el tejido empresarial español, el mercado laboral y financiero debilitados por la crisis derivada de la Pandemia COVID-19 hace difícil que las empresas, sobre todo las pequeñas y medianas puedan realizar aportaciones a planes de pensiones para sus empleados. En cualquier caso, a través de las 27 páginas que conforman el capítulo, el lector podrá adentrarse en el complejo régimen jurídico-tributario de los planes de pensiones. 
La obra concluye con un sexto capítulo que nos brinda de forma muy acertada unas reflexiones y propuestas en torno al futuro del sistema público de pensiones y la protección social complementaria. Tanto la crisis económica del 2008 como la actual por el COVID-19, demuestran como los sistemas de pensiones públicos de reparto garantizan con mayor seguridad jurídica y económica la vejez de las personas. Cierto es que ante los desafíos a los que tanto el sistema público como el privado se enfrentan, ambos necesitan ser reformados permanentemente con el fin de adaptarse a las nuevas realidades sociales y económicas. No obstante, no parece acertado aprovechar el contexto de presiones sobre los sistemas públicos de pensiones y sus imperfecciones para reducir la cuantía de sus prestaciones y que sea el sistema privado el que garantice unas pensiones adecuadas y suficientes. Los planes privados no deberían desarrollarse a costa del sistema público. Sin lugar a duda, con reformas correctamente planteadas, el sistema público es lo suficientemente sólido para hacer frente a los desafíos de las próximas décadas. Nuestro sistema ha sabido adaptarse durante más de medio siglo y no hay previsión seria para pensar que no pueda seguir haciéndolo con éxito. Cualquier proceso de reforma debe cumplir el compromiso constitucional de garantizar un sistema público que proporcione unas pensiones económicamente adecuadas y suficientes, y complementado de forma libre y voluntaria por otro de carácter privado. Tampoco puede negarse «la utilidad complementaria de los sistemas de capitalización como instrumento válido para aliviar la presión sobre las finanzas públicas» pero «debe seguir siendo un mecanismo complementario de carácter voluntario, nunca sustitutivo del sistema prestacional público». En cualquier caso, la responsabilidad de garantizar las pensiones públicas recae sobre los poderes públicos que tienen los recursos y las herramientas para asegurar una pensión digna. Como resaltan los autores en más de una ocasión, al final es política económica, política social, es decir, son decisiones políticas. En este sentido, se plantea la posibilidad de que el nivel contributivo reciba aportaciones complementarias con cargo a presupuestos generales del Estado o que las fuentes de financiación se refuercen mediante «técnicas de destope, cotización por ingresos reales de los trabajadores autónomos, aumentos de cotización por expulsión de personal a través de su sustitución por sistemas automatizados o robótica, prohibición sistemática de la reducción de cotizaciones sociales para llevar a cabo políticas de empleo o facilitar las reestructuraciones empresariales».

Entre las muchas propuestas de reformas y medidas que los autores proponen para los planes privados de pensiones, se puede resaltar las siguientes: garantizar una mayor universalización en la cobertura de los planes de pensiones; priorizar los planes de pensiones de empleo frente a otros mecanismos de previsión privados; el aseguramiento obligatorio de las prestaciones complementarias o la creación de un Fondo de Garantía como medida protectora de los intereses de los partícipes; potenciar los planes de pensiones del sistema de empleo a través de la negociación colectiva; y reducir las comisiones de gestión de los fondos de pensiones. 
En definitiva, esta nueva monografía de José Luis Monereo Pérez junto con Antonio Ojeda Avilés y Miguel Gutiérrez Bengoechea constituye un brillante estudio jurídico-crítico de la reforma de las pensiones públicas y de los planes privados de pensiones condicionada por los desafíos que plantean los cambios socioeconómicos que venimos asistiendo. Las muchas propuestas de reforma que en alguna ocasión puedan parecer parcialmente discordantes entre los académicos, reflejan la dificultad que entraña el tema. Sea como fuere, esta pluralidad de planteamientos demuestra que es posible encontrar vías de reformas para encontrar un equilibrio entre el sistema público sólido y las pensiones privadas complementarias. Por último, no podríamos terminar esta reseña sin resaltar la precisión y claridad expositiva de los autores que permite una mayor comprensión de un tema tan complejo como es el de la reforma del sistema de pensiones. 